\title{
Reflections on Sustainability Issues in Learning Object Development
}

\author{
Paula Carroll $^{1}$, Niall Flaherty ${ }^{2}$, Bard Ovenden ${ }^{2}$ \\ ${ }^{1}$ Management Information Systems, School of Business, University College Dublin, \\ Dublin, Ireland, ${ }^{2}$ Business eLearning, School of Business, University College Dublin, \\ Dublin, Ireland.
}

\begin{abstract}
Data science is a relatively new requirement in business curricula. Historically many business students have shied away from business statistics. We describe a project to create learning objects to enhance business students confidence and capabilities in performing statistical and analytics business tasks. In this paper we focus on the content development process, rather than the impact of the learning objects on student learning outcomes. We reflect on the steps in the learning object design and implementation project and conclude that the Plan, Act, Observe and Reflect iterative cycle worked well for the project team. We include recommendations on how this framework could be augmented to improve the sustainability of learning objects.
\end{abstract}

Keywords: Innovative Learning Materials; Learning Object Development; Quantitative Skills Development; Learning Object Sustainability. 


\section{Introduction}

The disruptive effect of the analytics movement has caused many business schools to refocus curricula to emphasise the importance of data analysis to support decision making. Davenport \& Harris (2007) outline how businesses can optimise business capabilities via analytics, thus positioning businesses who adopt an analytics approach to better compete. Mortenson et al. (2015) describe business analytics as a dianoetic management paradigm which they describe as of, or relating to thought, particularly to discursive reasoning rather than intuition. They describe the analytics movement as progression of normal science and note that what we come to know, we add to curriculum.

However, business students demonstrate a lack of interest in statistics and data analysis, despite the many career opportunities emerging in this area. In this paper we present one component of an action research project to engage business students with analytics. We describe the development of a set of short videos aimed at aiding improving students' understanding of both statistical concepts and the statistical language and symbols associated with the concepts. We summarise our experience in designing and creating the videos and reflect on sustainability of the approached we used.

\section{Business Analytics Education}

The business analytics movement has prompted the adaption of traditional business statistics courses to address the growing need for business graduates with an understanding of analytics and evidence supported decision-making.

However, the challenges of engaging business students with quantitative and statistical topics are well documented, see for example Stevens and Palocsay (2012) and Carroll and White (2017). Business students often feel that analysis and statistics are boring and not relevant to the real-world. They consider quantitative courses the most difficult and challenging courses in the business curricula. They perceive that analysis is required in business, but not that they may become responsible for performing or interpreting that analysis Cronin and Carroll (2015).

Business analytics undergraduate education is concerned not so much with the development of novel methods or software. Rather it relies on the statistics and computer science communities for those resources. Instead a knowledge of the appropriate methods and their underlying assumptions is what undergraduate business students need, so that they can model real-world problems and use the methods and software to solve the modelled problem. The challenge for business students is then to map a textual description of a problem to a mathematical or statistical encoding of the problem. 
Cañadas et al. (2018) note that students have difficulties transforming verbal reasoning (a real-world natural language representation) into algebraic symbols and vice versa. Yet mathematical and statistical symbols and language are required to encode the real-world problem into a format that can be solved by a computer (algorithm).

Gravemeijer et al. (2017) also remark that at school it is the teachers who formulate the (mathematical) problem and students who try to solve it. In contrast in the real-world, the challenge is to formulate a mathematical problem and try to get software to solve it.

The majority of undergraduate business students at University College Dublin, Ireland, enter the business programmes based on their grades in standard state exams. The programmes stipulate a minimum mathematics score as an entry requirement and students demonstrate varied mathematical abilities, ranging from meeting the minimum requirement, to the highest possible score in the state exam.

Business analytics education at University College Dublin has shifted away from teaching competencies that compete with what computers can do, and focuses on competencies that complement computer capabilities. Students are required to take core modules in data analysis and mathematics in their first year. We focus on the application of descriptive and inferencial statistics to support decision-making in a business context. Students use spreadsheet tools to perform analyses. Lecture content uses both natural language and the language and symbols of mathematics and statistics to connect concepts to practice. Our motivation for this approach is that algebraic symbols offer a common language to encode mathematical or statistical models of real-world business problems. However, our experience shows that many business students find the use of these symbols and language challenging.

Our response to the challenges outlined above is an overarching action research project to reflect on the learning resources and methods of delivery of the core data analysis module to engage business students with data analysis while remaining cognisant of assurance of learning concerns. By engaging with research and reflection on our own actions, we aim to identify subsequent developmental actions with the overall objective of improving the student experience of learning data analysis, and of improving their attainment of the module learning outcomes. We think of action research as a continual cycle of planning, acting, observing and reflecting.

Performing mental arithmetic activates similar brain activity as actually counting on our fingers. Dehaene et al. (1999) argue that the capacity for mathematical intuition requires both linguistic competence and visuo-spatial representations, and we believe the same is true in analytic thinking. By focusing on the design issues of quantitative learning resources, the resulting resources may enable some aspects of the mathematical thinking/ mental modelling processes in certain students. It should aid the acquisition of 
mathematical/statistical/data science concepts and assist students to achieve module statistical learning outcomes.

The use case in Section 3 describes a content design project aimed at creating a set of short videos that aim to improve students grasp of the use of symbols in statistical concepts and support their statistical literacy development by exploring the meaning of symbolic algebraic statements.

\section{Use Case: Developing Short Videos to aid Quantitative Skills}

The project was prepared using a Learning Object Metadata (LOM) schema (IEEE, 2002), with the aim of producing a sustainable content project which when set up initially, could then be iterated or repeated, without significant additional set up. The IEEE defines learning objects as "any entity, digital or non-digital, that may be used for learning, education or training". The IEEE LOM assists in creating structured descriptions of learning resources which are useful in collaborative projects to facilitate a shared understanding of the resources. LOM should support the sustainability of the resource and promote its re-use and deployment in virtual learning environments. Table 1 shows an extract of the LOM for the videos. The video learning outcomes are linked to the learning outcomes of the business modules taught by the PIs.

The initial time commitment included metadata creation, project scoping, script development, animation, audio recording, video editing, and project management. The College of Business eLearning team were able to provide advice on learning object development and met with PIs and their designer to offer guidance and support.

\subsection{Project Objective}

Some research shows that both linguistic and visuo-spatial cognitive processes are at work during quantitative problem solving. However, some business students find the use of statistical formulae daunting. This may act as a stumbling block if their focus is diverted to understanding the symbols (the linguistic bit), rather than developing an understanding of the statistical principles. Their focus is often on how to apply a formula, rather than understanding the insights (often visuo-spatial representations) that arise from the application of the formula. The objectives of these learning resources are to aid business students in developing statistical thinking capabilities, and to help develop awareness on their inherent statistical thinking in their everyday lives by presenting contextualised examples of the application of business statistics. These resources were chosen for their broad application within the subject area and programmes within the school. 
Table 1. Video Learning Object Summary

\begin{tabular}{|c|c|c|}
\hline Title & Learning Outcome & $\begin{array}{l}\text { Run time } \\
\text { (min: sec) }\end{array}$ \\
\hline $\begin{array}{l}\text { Calculating } \\
\text { Averages }\end{array}$ & Calculate the average or mean using algebraic symbols. & 03:07 \\
\hline $\begin{array}{l}\text { Interpreting } \\
\text { Averages }\end{array}$ & $\begin{array}{c}\text { Calculate, interpret and present useful statistical measurements from } \\
\text { large-scale data sets. }\end{array}$ & $01: 57$ \\
\hline $\begin{array}{c}\text { Sample } \\
\text { Variance }\end{array}$ & Calculate variance and standard deviation using algebraic symbols. & 02:54 \\
\hline $\begin{array}{l}\text { Interpreting } \\
\text { Variance }\end{array}$ & $\begin{array}{l}\text { Calculate, interpret and present the variance and standard deviation } \\
\text { of large-scale data sets. }\end{array}$ & 02:15 \\
\hline $\begin{array}{l}\text { Interpreting } \\
\text { Correlation }\end{array}$ & Interpret the correlation coefficient from large-scale data sets. & $02: 14$ \\
\hline
\end{tabular}

\subsection{Project Plan}

An action research framework was selected to help guide the project. The strength of action research lies in its focus on generating solutions to practical problems and its ability to empower practitioners (Koshy, 2009). PIs secured funding to recruit a research assistant with multimedia skills. Together they finalised the project scope and agreed deadlines and deliverables. The PIs produced project metadata (LOM) and developed scripts. We started by identifying topics where the lecturers saw a need for visual learning resources. The draft list of topics to be covered aligned to programme and modules outcomes. The designer produced animations to accompany the scripts. Animations were reviewed in an iterative process. Audio was recorded and overlaid, and project outputs were published on the school's media server with support from the College eLearning team.

\subsection{Project Implementation}

The PIs secured funding from a university learning initiative seed fund. The action research project plan followed a Plan, Act, Observe and Reflect iterative cycle. Principle Investigators initiated the project, researched the data and acquired funding, developed the project scope, engaged a designer who developed content, oversaw the production of the 
animations, evaluated the project, and sought revisions before releasing the content to students within the relevant modules on the virtual learning environment.

Design decisions in relation to font choices and colour schemes prioritised clarity, readability and accessibility. The voice-over actor was chosen as representative of the student's peer group for relatability. A background track was used to add audio depth. After Effects was selected as the animation tool for the project. This is a powerful animation and digital effects package, an industry standard for animation effects, which is widely available, with a firmly established skillset in the design industry. It allows the animation of hundreds of individual visual elements with multiple animated behaviours including position, scale, opacity and rotation. Sample screen shots are shown in Figures 1 and 2.

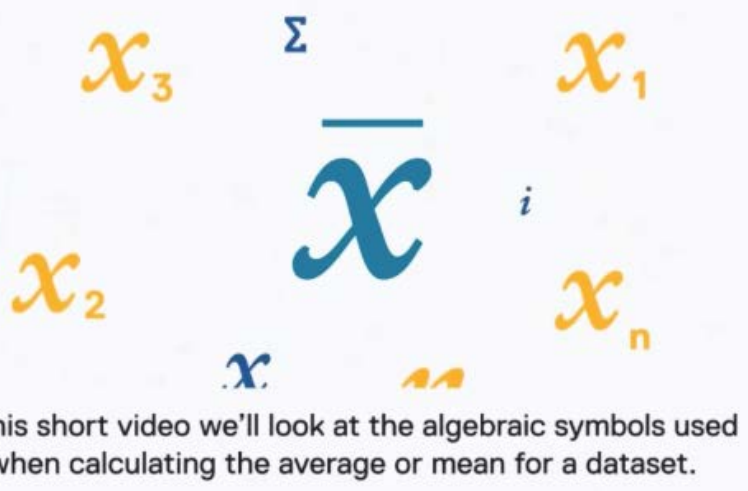

Figure 1. Calculating Averages [Video File]. Retrieved from https://qsblc.ucd.ie/videos/calculatingaverages_58778/

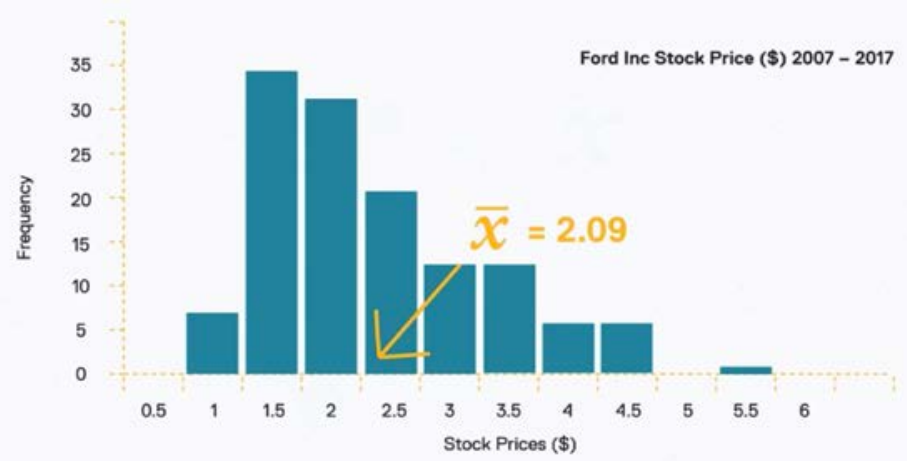

The average price for the stock over this period is $\$ 2.09$

Figure 2. Interpreting Averages [Video File]. Retrieved from https://qsblc.ucd.ie/videos/interpretingaverages_20147/ 
The designer produced storyboards for the initial animation and developed visual elements for the animations that were signed off by PIs.

There followed an iterative storyboarding process, where the designer worked with scripts provided by PIs, developed the imagery and created an outline. Following feedback from the PIs, scripts were refined, then the designer produced animations to bring the script to life. Text overlays were added to the imagery to summarise the script and re-enforce learnings. The animations were reviewed, and some small final edits made. The audio recordings for the voice-over were all produced after all the animations were completed and finalised.

\section{Recommendations and Conclusions}

This project was time-consuming and required a large commitment from the production team. It was challenging for PIs to fit these responsibilities in with everyday teaching and research responsibilities. The videos have been published on the Management Information Systems module MIS10090: Data Analysis for Decision Makers. We can collect viewing data for the videos which are hosted on our media server. Access can be controlled for the videos, but currently sign-in is not required to view the videos.

We discovered how important it is for the voice-over actor to be comfortable with the kind of content they will be reading, that extra time be allowed for the actor to prepare, and that the actor might benefit from being involved earlier, so that any apparent difficulties with the script could be reviewed. Leaving audio production to the end was reasonable but meant no real consideration of script changes were possible at that late stage.

We have explored remastering the audio with an instructor's voice, and have done this for the first video in our series. We also shortened and re-timed the animation, which took significantly less time than the initial creation, demonstrating the intended sustainability. During re-editing having to manipulate each of the many visual elements can complicate what should be small edits.

Greater sustainability could be provided in the future by connecting these visual elements to an external data-source. Connecting the project files to a data-source could be a significant undertaking but might offer another method of updating the content without major changes to the animation project files, and might represent another step towards sustainability for the project.

The action research cycle helped organise the project, for future design projects a design cycle may provide a more suitable framework, as it may provide for more explicit design iteration. 
While all source and project files were maintained by the designer, the importance of digital asset management became clearer when re-edits were required. A Digital Asset Management tool would be useful and a project archive should be kept so that all media, originals and derivatives are available if required. The further sustainability of any such project requires the underlying visual elements to be maintained. Where outside design assistance is sought, reproduction rights of all visual materials should be clarified.

At the conclusion of the project we have a completed series of videos which can be used to address student knowledge gaps for quantitative business subjects which are known to be problematic for business students, and have a roadmap which can be followed for the creation of future learning resources.

\section{References}

Davenport, T. H., \& Harris, J. G. (2007). Competing on analytics: The new science of winning. Harvard Business Press.

Dehaene, S., E. Spelke, P. Pinel, R. Stanescu, S. Tsivkin. 1999. Sources of mathematical thinking: Behavioral and brain-imaging evidence. Science 284 970-974.

Cañadas, M.C., M. Molina, A. del Río. (2018). Meanings given to algebraic symbolism in problem-posing. Educational Studies in Mathematics 98 19-37. doi:10.1007/s10649017-9797-9.

Carroll, P., \& White, A. (2017). Identifying Patterns of Learner Behaviour: What Business Statistics Students Do with Learning Resources. INFORMS Transactions on Education, 18(1), 1-13. doi:10.1287/ited.2016.0169.

Cronin, A., Carroll, P. (2015) Engaging business students in quantitative skills development. eJournal Bus. Ed. Scholarship of Teaching 9(1):119-131.

Gravemeijer, K., M. Stephan, C. Julie, F.L. Lin, M. Ohtani. (2017). What mathematics education may prepare students for the society of the future? International Journal of Science and Mathematics Education 15 105-123. doi:10.1007/s10763-017-9814-6.

IEEE (2002) Draft standard for learning object metadata. IEEE standard 1484.12.1. Technical report, Learning Technology Standards Committee, Institute of Electrical and Electronics Engineers, New York.

Koshy, V. (2009). Action research for improving educational practice: A step-by-step guide. Sage. ISBN 0 978-1-84860-159-8.

Mortensen, M. J., Doherty, N. F., \& Robinson. (2015). Operational research from Taylorism to Terabytes: A research agenda for the analytics age. European Journal of Operational Research, 3(241), 583-595. doi:10.1016/j.ejor.2014.08.029.

Stevens, S.P., S.W. Palocsay. (2012). Identifying addressable impediments to student learning in an introductory statistics course. INFORMS Transactions on Education 12 124-139. doi:10.1287/ited.1120.0085. 